\title{
Review: several factors are associated with the performance of D-dimer assays for detecting deep venous thrombosis
}

Heim SW, Schectman JM, Siadaty MS, et al. D-dimer testing for deep venous thrombosis: a metaanalysis. Clin Chem 2004;50: $1136-47$.

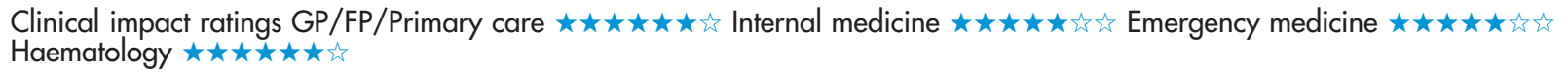

Q In symptomatic patients, what factors are associated with the performance of D-dimer assays for detecting lower extremity deep venous thrombosis (DVT)?

\section{METHODS}

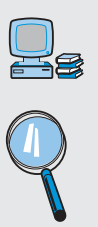

Data sources: Medline (February 1995 to October 2003) and bibliographies of relevant articles.

Study selection and assessment: diagnostic studies that calculated sensitivities and specificities or provided paired dato for comparing D-dimer assay results with lower extremity ultrasonography or venography for detecting acute DVT in symptomatic patients.

Outcome: diagnostic odds ratio (DOR) as a function of D-dimer assay while controlling for the reference standard, sample size, overall prevalence of disease, and patient mix of each study.

\section{MAIN RESULTS}

23 studies (3985 patients) met the selection criteria. Groups of Ddimer assays evaluated included first generation latex agglutination assays (D-dimer test, Dimertest, Dimertest II, and Nephelotex), second generation latex agglutination assays (Auto Dimertest, BC DDimer, IL Test, Liatest, LPIA, Tinaquant, and Turbiquant), membrane ELISAs (Instant IA and NyocCard), erythrocyte agglutination assays (SimpliRED), automated rapid ELFA (VIDAS), and microplate ELISAs (Asserachrom, Dimertest EIA, Dimertest GOLD EIA, Enzygnost, and Fibrinostika). Sensitivity varied from $51-100 \%$ and specificity from 19-94\%. Multivariate analysis showed that only the Dimertest, NycoCard, and Tinaquant assays differed (all with lower discriminant ability) from the VIDAS assay (table). Reference standards included ultrasonography (8 studies), venography (7 studies), and a combination of ultrasonography and venography (8 studies). Multivariate analysis showed that choice of venography as the reference standard was associated with better assay performance (table). 14 of 23 studies were done exclusively in outpatient populations with a prevalence of DVT that ranged from 20-68\%. The patient population of the other 9 studies was classified as mixed (for data analysis purposes), with 4 studies done exclusively in inpatient populations with a prevalence of $28-69 \%$. Multivariate analysis showed that a $10 \%$ increase in prevalence of DVT in the study population was associated with poorer assay performance (relative DOR $0.78,\{95 \% \text { CI } 0.67 \text { to } 0.95\}^{*}$ ). However, assay performance in mixed populations did not differ from that in outpatients (relative DOR 0.61, \{95\% CI 0.29 to 1.31$\}^{*}$ ).

\section{CONCLUSION}

In symptomatic patients, biochemical and technical characteristics of the assays, disease prevalence, and choice of reference standard are associated with the wide variation in performance of D-dimer assays for diagnosing lower extremity deep venous thrombosis.

*Information provided by author.

Abstract and commentary also appear in ACP Journal Club.

For correspondence: Dr S W Heim, University of Virginia Health System, Charlottesville, VA, USA. heims@virginia.edu

Source of funding: US Department of Health and Human Services.
Factors associated with the performance (diagnostic odds ratio [DOR]) of D-dimer assays for detecting deep venous thrombosis in symptomatic patients*

\begin{tabular}{lll}
\hline Variable & Comparisons & Relative DOR $(95 \% \mathrm{Cl})$ \\
\hline Assay & Dimertest $v$ VIDAS & $0.08(0.03$ to 0.20$)$ \\
& NycoCard $v$ VIDAS & $0.28(0.09$ to 0.90$)$ \\
Reference & Turbiquant $v$ VIDAS & $0.20(0.08$ to 0.52$)$ \\
standard & Ultrasonography or & $0.37(0.19$ to 0.74$)$ \\
& venography $v$ venography & \\
\hline
\end{tabular}

${ }^{*} \mathrm{Cls}$ provided by author. 